\title{
Effect of interleukin 17 on proteoglycan degradation in murine knee joints
}

\author{
Jean Dudler, Nicole Renggli-Zulliger, Nathalie Busso, Martin Lotz, Alexander So
}

\begin{abstract}
Objective-To evaluate the effect of murine interleukin 17 (IL17) on cartilage catabolism and joint inflammation by direct intra-articular injection of the cytokine into murine knee joints.

Methods-Knees of normal C57 B1 mice were injected once or repeatedly with recombinant IL17 or IL1ß. Inflammation was estimated by technetium-99m pertechnetate $\left({ }^{99} \mathrm{Tc}\right)$ uptake and histological scoring of tissue sections. Proteoglycan depletion was evaluated by histological scoring of safranin $O$ stained sections. Effects on proteoglycan synthesis were studied by ${ }^{35} \mathrm{SO}_{4}$ incorporation.

Results-A single intra-articular injection of IL17 (10 ng/knee) produced effects very similar to those of IL1ß (10 ng/knee). No inflammation was detected at six or 24 hours by ${ }^{99}$ Tc uptake. However, safranin $O$ staining showed depletion of proteoglycan at 48 hours. Repeated injections of IL17 induced joint inflammation and cartilage proteoglycan depletion as shown by histological scoring. Unlike IL1ß, proteoglycan depletion induced by IL17 seemed to be the result of increased degradation only, as no suppression of ${ }^{35} \mathrm{SO}_{4}$ incorporation was seen.
\end{abstract}

Conclusion-These findings confirm, in vivo, the catabolic effects of IL17 on cartilage. IL17 is thus the first T cell cytokine showing a direct catabolic effect on cartilage in addition to stimulatory effects on macrophages and synoviocytes, making it a potentially important cytokine in the pathogenesis of arthritis.

(Ann Rheum Dis 2000;59:529-532)

Rhumatologie,

Médecine Physique et

Rééducation, Centre

Hospitalier

Universitaire Vaudois,

CHUV - 1011

Lausanne, Switzerland

J Dudler

N Renggli-Zulliger

N Busso

A So

Division of Arthritis Research, The Scripps Research Institute, La Jolla, CA 92037, USA M Lotz

Correspondence to:

Dr Dudler

Email:

jdudler@chuv.hospvd.ch

Accepted for publication 15 February 2000

Interleukin 17 (IL17), is a glycosylated homodimeric protein of 150 amino acids cloned from an activated $\mathrm{T}$ cell line, ${ }^{1}$ showing about $57 \%$ of homology to the open reading frame of a lymphotrophic virus, Herpesvirus saimiri. ${ }^{1-3}$ IL17 is secreted only by activated memory CD4+ T cells, ${ }^{14}$ but its receptor is widely distributed, in particular in tissues of mesenchymal origin. ${ }^{235}$

$\mathrm{T}$ cells have a critical role in rheumatoid pathogenesis. IL17 was found to be highly produced by rheumatoid, but not osteoarthritic, synovium. ${ }^{6}$ Furthermore, most of the T cells within rheumatoid synovium show a Th1 pattern of cytokine production. ${ }^{78}$ Interestingly, only the Th1/Th0, but not Th2, subsets of CD4+ cell clones isolated from rheumatoid synovium produced IL17. ${ }^{9}$
In rheumatoid arthritis, $\mathrm{T}$ cells, macrophages, and mesenchymal cells all interact through autocrine, paracrine, and cell-contact pathways. IL17 may have an important role in this communication and interaction. It has been shown that IL17 can induce stromal cells to produce proinflammatory cytokines such as IL6, IL8, granulocyte colony stimulating factor, and prostaglandin $\mathrm{E}_{2} \cdot{ }^{10}$ IL17 induces IL6 and leukaemia inhibitory factor production by rheumatoid arthritis synoviocytes in a dose dependent manner, similarly to, but slightly less efficiently than, IL $1 \beta,{ }^{11}$ and stimulates the production and expression of IL1 $\beta$ and tumour necrosis factor $\alpha$ by human macrophages. ${ }^{12}$

Other in vitro studies have also shown that IL17 could potentially initiate a matrix degradative response directly in cartilage through the up regulation of nitric oxide, stromelysin, or IL $1 \beta$ in chondrocytes. ${ }^{13} 14$

Collectively, these observations suggest that IL17 may be an important factor in the initiation or maintenance of the $\mathrm{T}$ cell-dependent inflammation and cartilage matrix degradation in rheumatoid arthritis. The present in vivo study assessed the effects of IL17 on cartilage catabolism after intra-articular injection of the cytokine.

\section{Materials and methods}

ANIMALS

C57BL/Ola mice, 8 to 12 weeks old, were used for all experiments. The mice, originally obtained from Dr Carmeliet's laboratory (University of Leuven, Belgium), were bred in the animal facility at the Centre Hospitalier Universitaire Vaudois. The animals were fed a standard commercial diet and tap water freely. All animal procedures were done following standard procedures as required by our institution.
CYTOKINES AND INTRA-ARTICULAR INIECTIONS Recombinant murine IL17 was kindly supplied by Dr Satwant Narula (Schering-Plough Research Institute, Kenilworth, NJ). Recombinant murine IL $1 \beta$ was purchased from R\&D Systems (Abingdon, UK).

A total volume of $5 \mu \mathrm{l}$ containing either recombinant IL1 $\beta$ or IL17 in phosphate buffered saline (PBS) was injected through the infrapatellar ligament into the left knee joint space. The right knee was injected with $5 \mu$ of PBS as control. Briefly, mice were sedated with methoxyflurane (Metofane, Arovet, Zollikon, $\mathrm{CH})$, knees shaved with scissors, and the patellar ligament visualised through a small skin incision. Knees were then injected through the infrapatellar ligament using a $30 \mathrm{G}$ needle. 
Table 1 Histological scores of knee sections after a single intra-articular cytokine injection

\begin{tabular}{|c|c|c|c|c|}
\hline & \multicolumn{2}{|c|}{24 Hours after injection } & \multicolumn{2}{|c|}{48 Hours after injection } \\
\hline & Inflammation * & $\begin{array}{l}\text { Proteoglycan } \\
\text { depletion }^{\star}\end{array}$ & Inflammation * & $\begin{array}{l}\text { Proteoglycan } \\
\text { depletion }\end{array}$ \\
\hline Control & 0 & 0 & 0 & 0 \\
\hline IL1 $\beta$ (10 ng/knee) & $0 /+$ & 0 & $0 /+$ & $+/++\dagger$ \\
\hline IL17 (10 ng/knee) & 0 & 0 & + & +++ \\
\hline
\end{tabular}

Scoring was blinded for both variables. (Five animals per time point for each cytokine, all righ knees were used as controls). ${ }^{\star} \mathrm{p}>0.5$ by Kruskal-Wallis test. $\dagger \mathrm{p}<0.05$ Dunnett's test for multiple comparisons.
Table 2 Ratio of technetium-99m pertechnetate uptake six and 24 hours after a single injection of IL1 $\beta$ or IL17

\begin{tabular}{lll}
\hline & 6 Hours & 24 Hours \\
\hline IL1 $\beta(10 \mathrm{ng} / \mathrm{knee})$ & $1.001(0.147)$ & $1.098(0.114)$ \\
IL17 (10 ng/knee) & $0.996(0.120)$ & $1.013(0.117)$ \\
\hline
\end{tabular}

Ratios between experimental and control knee counts, are given as means (SD), (IL1 $\beta \mathrm{n}=9$, IL17 $\mathrm{n}=10$ ). No significant difference between IL1 $\beta$ and IL17 using an unpaired $t$ test.

NL) was added after cooling and counts determined in a $\beta$ scintillation counter. Results were expressed as a percentage of inhibition compared with PBS treated patellae.

MEASUREMENTS

Acute joint inflammation was determined using the technetium-99m pertechnetate $\left({ }^{99} \mathrm{Tc}\right)$ uptake method as originally described by Lens et al. ${ }^{15}$ Briefly, animals were sedated by intraperitoneal injection of pentobarbital ( 50 $\mu \mathrm{g} / \mathrm{g}$ of body weight) and $10 \mathrm{mCi}$ of ${ }^{99} \mathrm{Tc}$ in 0.2 $\mathrm{ml}$ saline injected subcutaneously in the neck region. Accumulation of the isotope was determined for both knees five minutes after the injection with an external gammacounter. Severity of inflammation was expressed as a ratio between the experimental knee, injected with recombinant IL $1 \beta$ or IL17, and the opposite control knee injected with PBS alone. Ratios higher than 1.1 are indicative of joint inflammation.

HISTOLOGY AND SCORING OF MURINE KNEE

JOINTS

Animals were killed, knees fixed in buffered formalin for seven days, and decalcified in $50 \%$ formic acid $/ 15 \%$ sodium formate for six additional days. After standard embedding in paraffin, $7.5 \mu \mathrm{m}$ saggital sections were prepared and stained with a trichrome stain - safranin $\mathrm{O}$, fast green, and Weighert's haematoxylin. Sections were scored in a blinded manner using an ordinal scale for inflammation from 0 to +++ , where 0 is normal and +++ is extensive inflammation and infiltration. Sections were scored for loss of safranin $\mathrm{O}$ staining as a measure of cartilage proteoglycan depletion using a scale from 0 to +++ , where 0 represents no depletion and +++ severe and mostly complete depletion of staining in the superficial layer.

CARTILAGE PROTEOGLYCAN SYNTHESIS

Cartilage proteoglycan synthesis was assayed by sulphate incorporation in explants of intact patellae. ${ }^{16}$ After intra-articular injection, mice where killed and patellae isolated by dissection. Patellae from mice in the identical experimental groups were pooled, washed in RPMI, and then pulsed for three hours with $25 \mu \mathrm{Ci}$ of ${ }^{35} \mathrm{SO}_{4}$ (NEN, Le Grand-Saconnex, $\mathrm{CH}$ ) in RPMI. The patellae were then washed thoroughly and fixed overnight in $4 \%$ non-buffered formalin. The next day, the patellae were decalcified for four hours in 5\% formic acid and the cartilage dissected using a $1 \mathrm{~mm}$ diameter punch biopsy tool. The isolated cartilage was transferred to a scintillation vial containing $0.5 \mathrm{ml}$ of Lumasolve Lumal LSD (Lumac LS$\mathrm{C} \mathrm{BV}$, Groningen, NL) as a solubiliser and incubated for eight hours at $60^{\circ} \mathrm{C}$. Ten millilitres of scintillation fluid (Lipoluma Lipophilic LSC cocktail, Lumac LSC BV, Groningen,

\section{STATISTICS}

Statistical analysis for inflammation and proteoglycan depletion scores was carried out with the Kruskal-Wallis rank test and Dunnett's test for multiple comparisons between groups. Comparisons of ${ }^{99} \mathrm{Tc}$ uptake and ${ }^{35} \mathrm{SO}_{4}$ incorporation were carried out using an unpaired $t$ test.

\section{Results}

MATRIX DEPLETION AFTER A SINGLE INTRA-ARTICULAR INJECTION OF IL17

A single injection of $10 \mathrm{ng}$ recombinant murine IL1 7 or IL1 $\beta$ for each knee produced similar effects. Histological evaluation at 24 and 48 hours after injection showed no oedema or haemorrhage and little leucocyte infiltration into the synovium (table 1 ). Neither IL1 $\beta$ nor IL17 produced detectable inflammation at six and 24 hours after the intra-articular injection as assessed by ${ }^{99} \mathrm{Tc}$ uptake (table 2).

Proteoglycan depletion as assessed by safranin $\mathrm{O}$ staining was not evident at 24 hours after the intra-articular injection, but statistically significant depletion of staining was seen at 48 hours after injection, for both IL $1 \beta$ and IL17 (table 1). The absence of increased technetium uptake and the low level of inflammation render it unlikely that the proteoglycan articular cells and most likely represents direct effects of IL17 on chondrocytes.

\section{JOINT INFLAMMATION AND MATRIX DEPLETION} AFTER REPEATED INTRA-ARTICULAR INJECTIONS OF IL17

To evaluate the effects of repeated cytokine injections, knees were injected three times at 48 hour intervals with 10 or $1 \mathrm{ng}$ of recombinant murine IL17 and the effects compared with repeated injections of $10 \mathrm{ng}$ of recombinant murine IL1 $\beta$. Mice were killed 24 hours after the last injection.

The histology of control knees showed, as expected from the trauma of repeated injections, a slight increase in inflammation compared with the controls after a single injection (table 3). More severe inflammation and loss of safranin $\mathrm{O}$ staining was seen in animals with repeated as compared with single cytokine injections. The lower dose of $1 \mathrm{ng}$ IL17 for each knee also induced significant effects; more severe changes were seen after injection of 10 ng for each knee (table 3). Figure 1 shows representative examples of the histological changes. loss is secondary to recruitment of extra- 
Table 3 Histological scores of knee sections after multiple intra-articular injections

\begin{tabular}{lll}
\hline & Inflammation & Proteoglycan depletion \\
\hline Control & + & $0 /+$ \\
IL1 $\beta(10 \mathrm{ng} / \mathrm{knee})$ & $+_{+\star}^{\star}$ & $++^{\star}$ \\
IL17 $(10 \mathrm{ng} / \mathrm{knee})$ & $++^{\star}$ & $++/+++^{\star}$ \\
IL17 $(1 \mathrm{ng} / \mathrm{knee})$ & $++^{\star}+$ & $+/++^{\star}+$ \\
\hline
\end{tabular}

Scoring was blinded for both variables. (Six animals per time point for each cytokine, all right knees were used as controls). Multiple comparisons using Dunnett's test. ${ }^{\star} \mathrm{p}<0.001$ versus control. $\nmid \mathrm{p}<0.05$ for IL1 7 and IL1 $\beta$ at $10 \mathrm{ng} / \mathrm{knee}$

Further dose-response studies were performed with two injections at 48 hour intervals using doses of $1,10,20$, and $50 \mathrm{ng}$ of IL17 for each knee and compared with control IL1 $\beta$ (10 $\mathrm{ng} / \mathrm{knee})$. At all cytokine doses tested an inflammatory infiltration of the joint and a more severe degradation of cartilage proteoglycan was seen than after a single injection. Maximum effects of IL17 were seen at 10 ng/knee. The higher IL17 doses (20 and 50 $\mathrm{ng} / \mathrm{knee}$ ) did not induce more severe inflammation or proteoglycan loss (four mice per group, data not shown).

IL17 HAS NO EFFECT ON PROTEOGLYCAN SYNTHESIS IN VIVO

IL1 $\beta$ has a longlasting suppressive effect on proteoglycan synthesis after intra-articular injection. ${ }^{17}$ As IL17 has similar effects on proteoglycan degradation after single or repeated intra-articular injections, proteoglycan synthesis in IL17 treated explant cultures of intact patellae were analysed and compared with the effects of IL1 $\beta$. Firstly, patellae were incubated for 24 hours ex vivo with either IL $1 \beta$ or IL17 at $10 \mathrm{ng} / \mathrm{ml}$. IL1 $\beta$ induced the expected decrease in proteoglycan synthesis, but no inhibition was seen with IL17. The
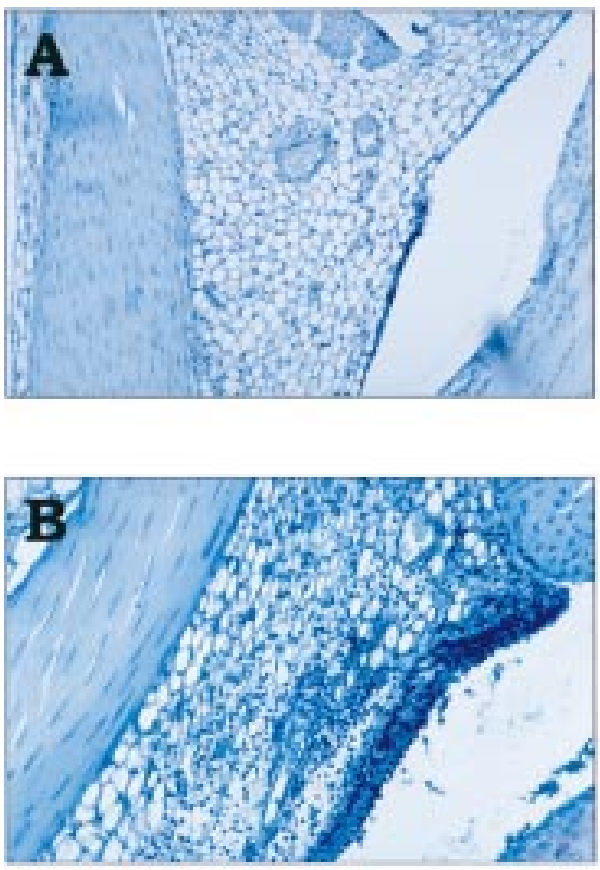

Figure 1 Histological changes induced by intra-articular cytokine injection. Knee joints were harvested 24 hours after the last cytokine injection. Standard $7.5 \mu \mathrm{m}$ paraffin embedded saggital knee sections were stained with safranin $O$, fast green, and Weighert's haematoxylin $(\times 40)$. ( $A$ and $C$ ) Control knees, minimum inflammation and proteoglycan depletion; $(B$ and $D)$ moderate to severe inflammation with infiltration and exudation and proteoglycan depletion in an interleukin 17 injected knee.

Table 4 Comparison of IL1 $\beta$ and IL17 effects on proteoglycan synthesis rate ex vivo and in vivo

\begin{tabular}{lll}
\hline & Ex vivo & In vivo \\
\hline Control & $1228(510)$ & $11753(2716)$ \\
IL1 $(10 \mathrm{ng} / \mathrm{knee})$ & $651(328)^{\star}$ & $8070(1729)^{\star}$ \\
IL17 (10 ng/knee) & $1194(217) \dagger$ & $10795(117) \dagger$ \\
IL17 (1 ng/knee) & $1327(296) \dagger$ & $10649(3130) \dagger$ \\
\hline
\end{tabular}

Counts (cpm/patella) are given as means $(\mathrm{SD}) .{ }^{\star} \mathrm{p}<0.01$ versus control; tp NS versus control using an unpaired $t$ test.

same observation was obtained in vivo after a single intra-articular injection of $10 \mathrm{ng}$ of IL17 or IL1 $\beta$ in each knee, where proteoglycan synthesis was decreased after injection of IL1 $\beta$, but not IL17 (table 4).

\section{Discussion}

IL17 and its receptor have no homology with known cytokines and cytokine receptors, suggesting that they represent new gene families. Additional members of this cytokine/receptor family have not yet been identified but are likely to exist. The characterisation of IL17 functions has shown that it can induce the expression of proinflammatory genes, such as cytokines, metalloproteinases, and inducible nitric oxide synthase, in various cell types, including mononuclear phagocytes, synoviocytes, and chondrocytes.

IL17 activates in chondrocytes the mitogenactivated protein kinases cascade and the transcription factor $\mathrm{NF}-\kappa \mathrm{B}$, which are known for their role in the induction of inflammatory and matrix degradative responses in arthritis. ${ }^{14}$ Our study is the first analysis of the effects of IL17 induced by the in vivo administration of the cytokine. IL17 injections in normal murine knee joints reproduce many of the characteristics of IL1, a prototypic proinflammatory and
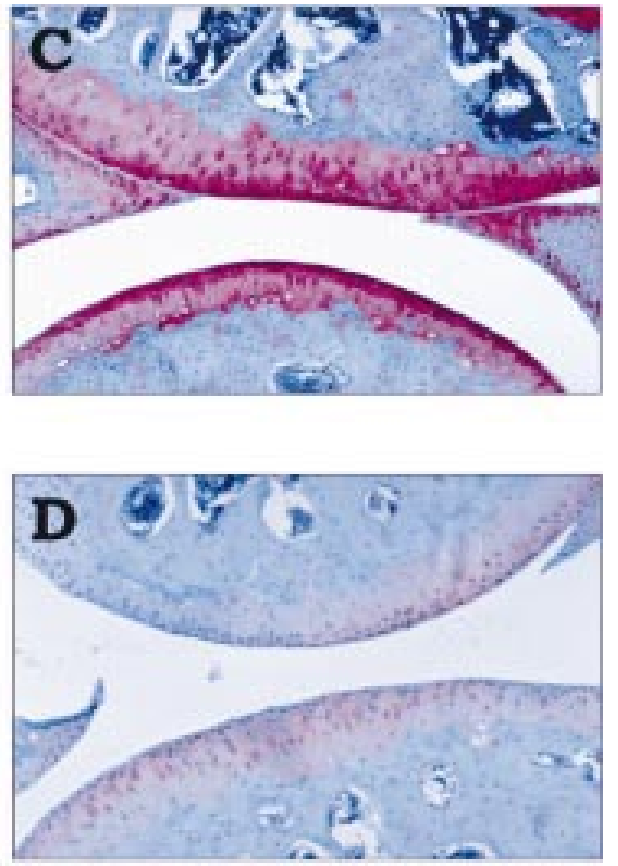
matrix degradative cytokine. ${ }^{17-19}$ As reported for IL1, depletion of proteoglycan seems to result from a local action of IL17 on cartilage as joint inflammation and cell recruitment are very mild. ${ }^{17}$ On the contrary, and unlike IL $1 \beta$, where prolonged suppression of proteoglycan synthesis appears as a key factor, ${ }^{20}$ our data indicate that IL17 induces proteoglycan loss primarily through increased degradation without a detectable change in biosynthesis rate.

Similar to other proinflammatory cytokines, IL17 also has an indirect catabolic effect on cartilage. IL17 can induce synoviocytes and macrophages to produce several other cytokines, and recent studies have underlined the role of IL17 in mediating interactions between $\mathrm{T}$ cells, mesenchymal cells, and macrophages. ${ }^{10-12}$ From this point of view, IL17 is certainly an interesting target for therapeutic intervention in rheumatoid arthritis. This cytokine, which is exclusively produced by $\mathrm{T}$ cells, is present in high amounts in rheumatoid synovial tissue and its inhibition may result in anti-inflammatory $\mathrm{T}$ cell targeted treatment. IL17 has been shown to stimulate osteoclast formation and bone resorption in patients with rheumatoid arthritis, ${ }^{2122}$ and as the first $\mathrm{T}$ cell cytokine that can directly affect cartilage, bone, and induce other mediators of inflammation by stimulating mesenchymal cells, its inhibition may affect the so-called non- $T$ cell pathways in joint destruction and prevent joint erosions. This hypothesis needs to be confirmed by the use of specific blocking agents, such as soluble IL1 7 receptors, in animal models of arthritis as no direct injection of a single or even combination of cytokines reproduces the complexity of the arthritic process. Such studies would certainly lead to a better understanding of the role of IL17 in the pathogenesis of rheumatoid arthritis.

We thank Véronique Péclat for her valuable technical help with the histology work. This work was supported in part by the Jean and Linette Warnery Foundation for Research on Rheumatoid Arthritis.

1 Rouvier E, Luciani MF, Mattei MG, Denizot F, Golstein P. CTLA-8, cloned from an activated T cell, bearing AU-rich messenger RNA instability sequences, and homologous to a herpesvirus saimiri gene. I Immunol 1993:150:5445-56.

2 Yao Z, Fanslow WC, Seldin MF, Rousseau AM, Painter SL Comeau MR, et al. Herpesvirus saimiri encodes a new cytokine, IL-17, which binds to a novel cytokine receptor. cytokine, IL-17, which bin

3 Yao Z, Painter SL, Fanslow WC, Ulrich D, Macduff BM, Spriggs MK, et al. Human IL-17: a novel cytokine derived Spriggs MK, et al. Human IL-17: a novel cyto
from T cells. J Immunol 1995;155:5483-6.
4 Kennedy J, Rossi DL, Zurawski SM, Vega Jr F, Kastelein RA, Wagner JL, et al. Mouse IL-17: a cytokine preferentially expressed by alpha beta TCR + CD4-CD8-T cells. J Interferon Cytokine Res 1996;16:611-17.

5 Yao Z, Spriggs MK, Derry JM, Strockbine L, Park LS, VandenBos T, et al. Molecular characterization of the human interleukin (IL)-17 receptor. Cytokine 1997;9:794800 .

6 Chabaud M, Durand JM, Buchs N, Fossiez F, Page G, Frappart L, et al. Human interleukin-17 - a T cell-derived
proinflammatory cytokine produced by the rheumatoid proinflammatory cytokine produced by the
synovium. Arthritis Rheum 1999;42:963-70.

7 Miossec P, van den Berg W. Th1/Th2 cytokine balance in arthritis. Arthritis Rheum. 1997;40:2105-15.

8 Dolhain RJ, van der Heiden AN, ter Haar NT, Breedveld FC, Miltenburg AM. Shift toward T lymphocytes with a T helper 1 cytokine-secretion profile in the joints of patients with rheumatoid arthritis. Arthritis Rheum 1996;39: 1961-9.

9 Aarvak T, Chabaud M, Miossec P, Natvig JB. IL-17 is produced by some proinflammatory Th1/Th0 cells but not by Th2 cells. J Immunol 1999;162:1246-51.

10 Fossiez F, Djossou O, Chomarat P, Flores-Romo L, Ait-Yahia S, Maat C, et al. T cell interleukin-17 induces stromal cells to produce proinflammatory and hematopoietic cytokines [see comments]. J Exp Med 1996;183:2593603.

11 Chabaud M, Fossiez F, Taupin JL, Miossec P. Enhancing effect of IL-17 on IL-1-induced IL-6 and leukemia inhibitory factor production by rheumatoid arthritis synoviocytes and its regulation by Th2 cytokines. J Immunol 1998;161: 409-14.

12 Jovanovic DV, Di Battista JA, Martel-Pelletier J, Jolicoeur FC, He Y, Zhang M, et al. IL-17 stimulates the production and expression of proinflammatory cytokines, IL-beta and TNF-alpha, by human mato 3513-21.

13 Attur MG, Patel RN, Abramson SB, Amin AR. Interleukin-17 up-regulation of nitric oxide production in human osteoarthritis cartilage. Arthritis Rheum 1997;40: 1050-3.

14 Shalom-Barak T, Quach J, Lotz M. Interleukin-17-induced gene expression in articular chondrocytes is associated with activation of mitogen-activated protein kinases and NFkappaB. J Biol Chem 1998;273:27467-73.

15 Lens JW, van den Berg WB, van de Putte LB. Quantitation of arthritis by $99 \mathrm{mTc}$-uptake measurements in the mouse knee-joint: correlation with histological joint inflammation scores. Agents Actions 1984;14:723-8.

16 de Vries BJ, van den Berg WB, Vitters E, van de Putte LB. Quantitation of glycosaminoglycan metabolism in anatomically intact articular cartilage of the mouse patella: in vitro and in vivo studies with ${ }^{35} \mathrm{~S}$-sulfate, ${ }^{3} \mathrm{H}$-glucosamine, and ${ }^{3} \mathrm{H}$-acetate. Rheumatol Int 1986;6:273-81.

17 van de Loo AA, van Beuningen HM, van Lent PL, van den Berg WB. Direct effect of murine rIL-1 on cartilage Berg WB. Direct effect of murine rIL-1 on cartil
metabolism in vivo. Agents Actions 1989;26:153-5.

18 van Beuningen HM, Arntz OJ, van den Berg WB. In vivo effects of interleukin-1 on articular cartilage. Prolongation of proteoglycan metabolic disturbances in old mice. Arthritis Rheum 1991;34:606-15.

19 van de Loo AA, van den Berg WB. Effects of murine recombinant interleukin 1 on synovial joints in mice: measurement of patellar cartilage metabolism and joint inflammation. Ann Rheum Dis 1990;49:238-45.

20 van den Berg WB, van de Loo FA, Zwarts WA, Otterness IG. Effects of murine recombinant interleukin 1 on intact homologous articular cartilage: a quantitative and autoradiographic study. Ann Rheum Dis 1988;47:855-63.

21 Kotake S, Udagawa N, Takahashi N, Matsuzaki K, Itoh K, Ishiyama S, et al. IL-17 in synovial fluids from patients with rheumatoid arthritis is a potent stimulator of osteoclastogenesis. J Clin Invest 1999;103:1345-52.

22 Van Bezooijen RL, Farih-Sips HC, Papapoulos SE, Lowik CW. Interleukin-17: a new bone acting cytokine in vitro. J Bone Miner Res 1999;14:1513-21. 